\title{
A Review on Cough Augmentation Techniques: Assisted Inspiration, Assisted Expiration and Their Combination
}

\author{
Arietta SPINOU ${ }^{1}$ \\ ${ }^{1}$ Population Health Sciences, Faculty of Life Sciences and Medicine, King's College London, \\ United Kingdom
}

Received October 5, 2019

Accepted November 18, 2019

\section{Summary}

Cough is an important mechanism of airway clearance. In patients who present weak and ineffective cough, augmentation techniques aim to assist or simulate the maneuver. These techniques target different phases of the cough cycle, mainly the inspiratory and expiratory phases, through assisted inspiration, assisted expiration and their combination. They include the manual hyperinflation, ventilator hyperinflation, glossopharyngeal breathing, manually assisted cough and mechanical insufflatorexsufflator, each applied individually or in different combinations. The aim of this review is to investigate the effectiveness and safety of cough augmentation techniques. Findings support that all commonly used techniques can theoretically improve airway clearance, as they generate higher cough peak flows compared to unassisted cough. Still, the studies assessing cough augmentation present considerable limitations and the direct comparison of different techniques is challenging. Current evidence indicate that cough peak flow shows higher increase with the combination of assisted inspiration and expiration, and improvement is greater in patients with lower unassisted values. Associated adverse events are infrequent.

\section{Key words}

Cough augmentation - Cough assist - Airway clearance • Manually assisted cough $\bullet$ Hyperinflation • Mechanical insufflatorexsufflator

\section{Corresponding author}

Arietta Spinou, Department of Population Health Sciences, Faculty of Life Sciences and Medicine, King's College, Guy's campus, Second Floor, Addison House, SE1 1UL, London, UK.

Email: arietta.spinou@kcl.ac.uk

\section{Introduction}

Cough is the physiological defense system of airway clearance along with the mucociliary escalator (Widdicombe and Fontana 2006). It is also a troublesome symptom that can be frequent and vigorous, and has the potential to serve as a measure of disease (Birring et al. 2003, Spinou and Birring 2014, Lee et al. 2017, Spinou et al. 2017). Still, on the opposite side of this spectrum, cough can be absent, weak and inadequate to clear the airways (Spinou 2018). When it does not generate effective airflows to achieve airway clearance, cough augmentation techniques can support one or more of the cough inspiratory, compressive, and expiratory phases (McCool 2006, Spinou 2018). These techniques are categorized into assisted inspiration, assisted expiration, or a combination of assisted inspiration and expiration, and include the manual hyperinflation, ventilator hyperinflation, glossopharyngeal breathing, manually assisted cough (MAC) and mechanical insufflatorexsufflator (MI-E), each applied individually or in different combinations (Chatwin et al. 2018).

Cough augmentation is commonly used in neuromuscular diseases, neurological weakness, spinal cord injury, and critically ill intubated and mechanically ventilated patients (Rose et al. 2014, Prevost et al. 2015, Hov et al. 2018). It is applied in acute and long-term settings and aims to reduce mucus retention and consequently respiratory infections and the risk of respiratory failure. Several studies investigate the cough augmentation techniques. The aim of this narrative review is to investigate the effectiveness and safety of the 
main cough augmentation techniques and their combination.

\section{Effects of cough augmentation on cough peak flow}

\section{Assisted inspiration}

Cough augmentation techniques that target the inspiratory phase of cough include the manual hyperinflation, ventilator hyperinflation and glossopharyngeal breathing (Chatwin et al. 2018). Manual hyperinflation, bagging or breath stacking aims to increase the inspiratory volume and ultimately result in higher expiratory airflow at the expulsive phase of cough (Paulus et al. 2012, Spinou 2018). Bagging involves delivering an inspiratory volume to the patient during inspiration, usually until maximum insufflation capacity, at a low inspiratory flow, with an inspiratory pause and then quick release to provide a high expiratory flow (Paulus et al. 2012). Application of the manual hyperinflation can be via a non-resuscitation bag, a resuscitation bag with one-way valve adjustment, or a resuscitation bag with the patient using glottic closure to retain the air volume in multiple breaths (Denehy 1999, Crowe et al. 2006, Toussaint et al. 2009). In the ventilator hyperinflation, mechanical means deliver positive pressure through adjusting the mechanical ventilation settings in critically ill patients (Dennis et al. 2012). Alternative devices deliver inspiratory positive pressure, such as the intermittent positive pressure breathing (IPPB), non-invasive ventilator (NIV), and insufflation using the MI-E (Trebbia et al. 2005, DohnaSchwake et al. 2006, Mellies and Goebel 2014). Glossopharyngeal breathing is a specific way of breathing to increase inspiratory volume, which aims to hyperinflation, increases the maximum insufflation capacity and serves as a safety option for ventilatordependent patients in events of machine failure (Feigelson et al. 1956, Bach et al. 1993, Bianchi et al. 2004, Nygren-Bonnier et al. 2018).

Several studies have shown that assisted inspiration techniques increase the cough peak flow (CPF) alone or in combination with other cough augmentation techniques compared to unassisted cough in patients with neuromuscular disease, Duchenne muscular dystrophy, amyotrophic lateral sclerosis, spinal cord injury and patient using mechanical ventilation due to post-poliomyelitis muscle weakness (Kirby et al. 1966, Kang et al. 2005, Kang et al. 2006, Toussaint et al. 2009,
Sarmento et al. 2017, Bach et al. 1993). Although the increase is higher to unassisted cough, it is generally lower than the increase from expiration or the combination of inspiration and expiration cough augmentation. Moreover, hyperinflation techniques are more effective in the absence of scoliosis (Marques et al. 2014). One study found that air stacking is more effective than the MAC, although the combination of both is more effective than any of these two alone (mean \pm standard deviation (SD) CPF unassisted $138 \pm 70 \mathrm{l} / \mathrm{min}$, MAC $204 \pm 75 \mathrm{l} / \mathrm{min}$, hyperinflation $236 \pm 68 \mathrm{l} / \mathrm{min}$, and hyperinflation with MAC $302 \pm 781 / \mathrm{min}$, all $\mathrm{p}<0.0001$ ) (Ishikawa et al. 2011). Assisted inspiration generates higher CPF increase in patients with lower vital capacity (Kang and Bach 2000).

\section{Assisted expiration}

Assisted expiration techniques include the MAC and exsufflation using MI-E (Chatwin et al. 2018). Their aim is to support the expiratory phase of cough to generate an expiratory flow bias and achieve mucus mobilization based on the two-phase gas-liquid interaction (Spinou 2018). MAC uses external mechanical force or compression applied on the thoracic, abdominal, and thoraco-abdominal areas during expiration (Sivasothy et al. 2001, Spinou 2018). The technique is applied by therapists, carers or patients who use self-assistance (Bianchi et al. 2014, Kan et al. 2018). The exsufflation involves applying the expiratory phase settings of the MI-E during expiration, without using the other MI-E settings (Mustfa et al. 2003).

Most studies of assisted expiration have investigated MAC and only a few investigated MI-E exsufflation only (Chatwin et al. 2003, Mustfa et al. 2003). Studies indicate that MAC increases the CPF in patients with expiratory muscle weakness compared to unassisted cough in neuromuscular disease, amyotrophic lateral sclerosis, Duchenne muscular dystrophy and spinal cord injury (Braun et al. 1984, Jaeger et al. 1993 Mustfa et al. 2003, Trebbia et al. 2005, Toussaint et al. 2009). This improvement is higher compared to assisted inspiration techniques alone and lower than when the techniques of assisted inspiration and expiration are combined. A study in 28 patients with Duchenne muscular dystrophy showed that CPF (mean $\pm \mathrm{SD}$ ) is higher with the combination of the MAC with manual hyperinflation using a resuscitation bag $(292 \pm 86 \mathrm{l} / \mathrm{min})$, compared to the techniques alone, MAC (231 $\pm 81 \mathrm{l} / \mathrm{min})$, hyperinflation $(225 \pm 80 \mathrm{l} / \mathrm{min})$, and unassisted cough 
(171 \pm 67 1/min) (Brito et al. 2009). In mechanically ventilated patients, CPF was also higher when MAC was applied with an increased positive end-expiratory pressure and inspiratory time compared to MAC alone (112.3 $\pm 15.6 \mathrm{l} / \mathrm{min}$ versus $95.8 \pm 18.3 \mathrm{l} / \mathrm{m}, \mathrm{p}<0.05$ ) (Silva et al. 2012). MAC produced higher CPF than unassisted cough and electrically stimulated coughs in 24 patients with spinal cord injury (Jaeger et al. 1993). Interestingly, a study with patients with amyotrophic lateral sclerosis (21 bulbar vs. 26 non bulbar) showed that CPF (mean \pm SD) was higher compared to unassisted cough (178 \pm 61 vs. $217 \pm 84 \mathrm{l} / \mathrm{min})$ using MI-E exsufflation only $(225 \pm 76$ vs. $279 \pm 87 \mathrm{l} / \mathrm{min})$, vs. MAC (197 \pm 63 vs. $244 \pm 831 / \mathrm{min})$, insufflation (188 \pm 64 vs. $226 \pm 86 \quad 1 / m i n)$, and MI-E (212 \pm 75 vs. $264 \pm 73$ 1/min) (Mustfa et al. 2003).

\section{Combination of assisted inspiration and expiration}

The combination of assisted inspiration and expiration has various forms and studies have used a variety of means to combine the aforementioned techniques. Assisted cough using a MI-E device is a common method that aims to simulate the cough maneuver by altering the delivery of positive pressure (insufflation) and negative pressure (exsufflation) to the airways, with manual or automatical pausing in between (compression) (Bach 1993, Homnick 2007). Furthermore, at the end of the MI-E treatment there is application of insufflation, which provides inspiration to appropriate functional residual capacity (Hull et al. 2012). MI-E can be used with various interfaces on patients who are spontaneously breathing, intubated or tracheotomized (Miske et al. 2004, Bach et al. 2014).

Effectiveness and individual thresholds of tolerance guide the application of the MI-E pressures. Still, insufflation (inspiratory phase) and exsufflation (expiratory phase) pressures of $40 \mathrm{mmHg}$ have been generally suggested (Fauroux et al. 2008). Clinically, patients receive $5-15 \mathrm{mmH}_{2} \mathrm{O}$ lower pressure than it is indicated in the MI-E device settings (Fauroux et al. 2008). In the presence of endotracheal tube or tracheostomy, the tube diameter increases the resistance and requires greater pressure to achieve higher expiratory flows, so pressures range from $38 \mathrm{mmHg}$ to $51 \mathrm{mmHg}$ (Guerin et al. 2011). Lung models have shown that higher pressures of exsufflation than insufflation and higher times of insufflation than exsufflation can increase expiratory flow (Gomez-Merino et al. 2002, Striegl et al.
2011). The exsufflation pressures are usually greater than the insufflation pressures in absolute value and also the exsufflation duration is longer than the insufflation (Chatwin and Simonds 2019). Higher pressures may be required in patients with lower unassisted $\mathrm{CPF}$, whilst MI-E application in patients with amyotrophic lateral sclerosis might need lower pressures from other neuromuscular disease patients because there is evidence of upper airway collapse in flexible trans-nasal fibre-optic laryngoscopy (Andersen et al. 2017, Chatwin et al. 2018). Still in clinical practice, the pressures applied vary amongst patients and a European survey found that age is also a factor that results in differences on the applied pressures, with younger patients using lower pressures than older (Hov et al. 2018, Chatwin and Simonds 2019).

Many cross-over studies indicate that the increase of the CPF is higher when MAC is combined with assisted inspiration techniques and the MI-E generates higher PCF compared to unassisted cough and cough augmentation techniques in isolation (Kirby et al. 1966, Bach 1993, Bach et al. 1993, Morrow et al. 2013, Kim et al. 2016, Sancho et al. 2017). Breath stacking with the addition of MAC and also MI-E produced greater CPF compared to unassisted cough in patients with muscle weakness due to post-poliomyelitis (Bach et al. 1993). Breath stacking in combination with MAC generated the higher increase of CPF compared to the stand alone techniques in 179 patients with neuromuscular disease (Toussaint et al. 2009). The combination of IPBB with MAC showed a greater increase in CPF than MAC or IPPB alone in 10 patients with neuromuscular disease (Trebbia et al. 2005).

There was a significant increase in the PCF in bulbar and non-bulbar patients compared to unassisted cough (Mustfa et al. 2003), in a randomized cross-over study of MAC, insufflation using MI-E, exsufflation using MI-E and MI-E in 21 bulbar and 26 non bulbar patients with amyotrophic lateral sclerosis. MI-E produced higher CPF than MAC with or without manual hyperinflation or bi-level ventilator hyperinflation in 16 patients with amyotrophic lateral sclerosis, and there was no difference between the bulbar and non-bulbar groups (Senent et al. 2011). MI-E also produced higher CPF compared to unassisted cough in 17 children with Duchenne muscular dystrophy, spinal muscular atrophy and other myopathies during a clinically stable stage (192 \pm 99 1/min vs. $162 \pm 97$ 1/min) (Fauroux, Guillemot et al. 2008). Similar results were shown in 21 patients with muscle weakness and NIV ventilator users, mean \pm SD 
CPF of unassisted cough $109 \pm 621 / \mathrm{min}$, air stacking $202 \pm 641 / \mathrm{min}, \mathrm{MAC} 256 \pm 77 \mathrm{1} / \mathrm{min}$ and MI-E $448 \pm 61$ 1/min, $\mathrm{p}<0.001$ (Bach 1993).

In a randomized study with an age-matched historical control, 22 patients with neuromuscular weakness generated greater increase in the CPF with MIE compared to unassisted cough, MAC, assisted cough using NIV, and exsufflation using MI-E ( $\mathrm{p}<0.001)$ (Chatwin et al. 2003). CPF was higher when MI-E was combined with MAC in a study with 40 patients with neuromuscular disease and respiratory muscle dysfunction. The mean \pm SD CPF during MAC with MIE was $202.4 \pm 46.61 / \mathrm{min}$ compared to the unassisted cough, hyperinflation with MAC, and MI-E, 95.7 \pm 40.5 , 155.9 $\pm 53.1,177.2 \pm 33.9$, respectively (Kim et al. 2016). A study with 12 patients with Duchenne muscular dystrophy found that MI-E with MAC generated higher CPF $(240 \pm 38 \mathrm{l} / \mathrm{min})$ compared to MAC $(113 \pm 32 \mathrm{l} / \mathrm{min})$ or MI-E (199 \pm 40 1/min) alone, hyperinflation with MAC $(224 \pm 62 \mathrm{l} / \mathrm{min})$, hyperinflation without MAC $(170 \pm 30$ $1 / \mathrm{min})$, and unassisted cough $(59 \pm 34 \mathrm{1} / \mathrm{min})$, all higher than unassisted cough, $\mathrm{p}<0.01$ (Kikuchi, Satake et al. 2018). Still, patients who reached CPF of $300 \mathrm{l} / \mathrm{m}$ using hyperinflation and MI-E did not have a higher CPF by adding MAC, probably because the cough effort from the combination of two exceeds the capacity of the device for pressure (Lacombe et al. 2014, Kim, Choi et al. 2016).

In contrast to the previous studies, hyperinflation using IPPB with MAC resulted in greater CPF increase than MI-E with or without MAC in 18 patients with neuromuscular disease and severe respiratory muscle dysfunction (Lacombe et al. 2014). In a randomized controlled trial with 26 patients with amyotrophic lateral sclerosis with bulbar or nonbulbar dysfunction, CPF of MAC combined with maximum insufflation or with MI-E was lower in the bulbar subgroup of seven patients who had unassisted CPF $<2701 /$ min compared to the other patients. These authors suggested that MI-E is ineffective in patients with bulbar dysfunction who generate maximum insufflation capacity $>11$ and unassisted PCF $<162$ 1/min (Sancho, Servera et al. 2004).

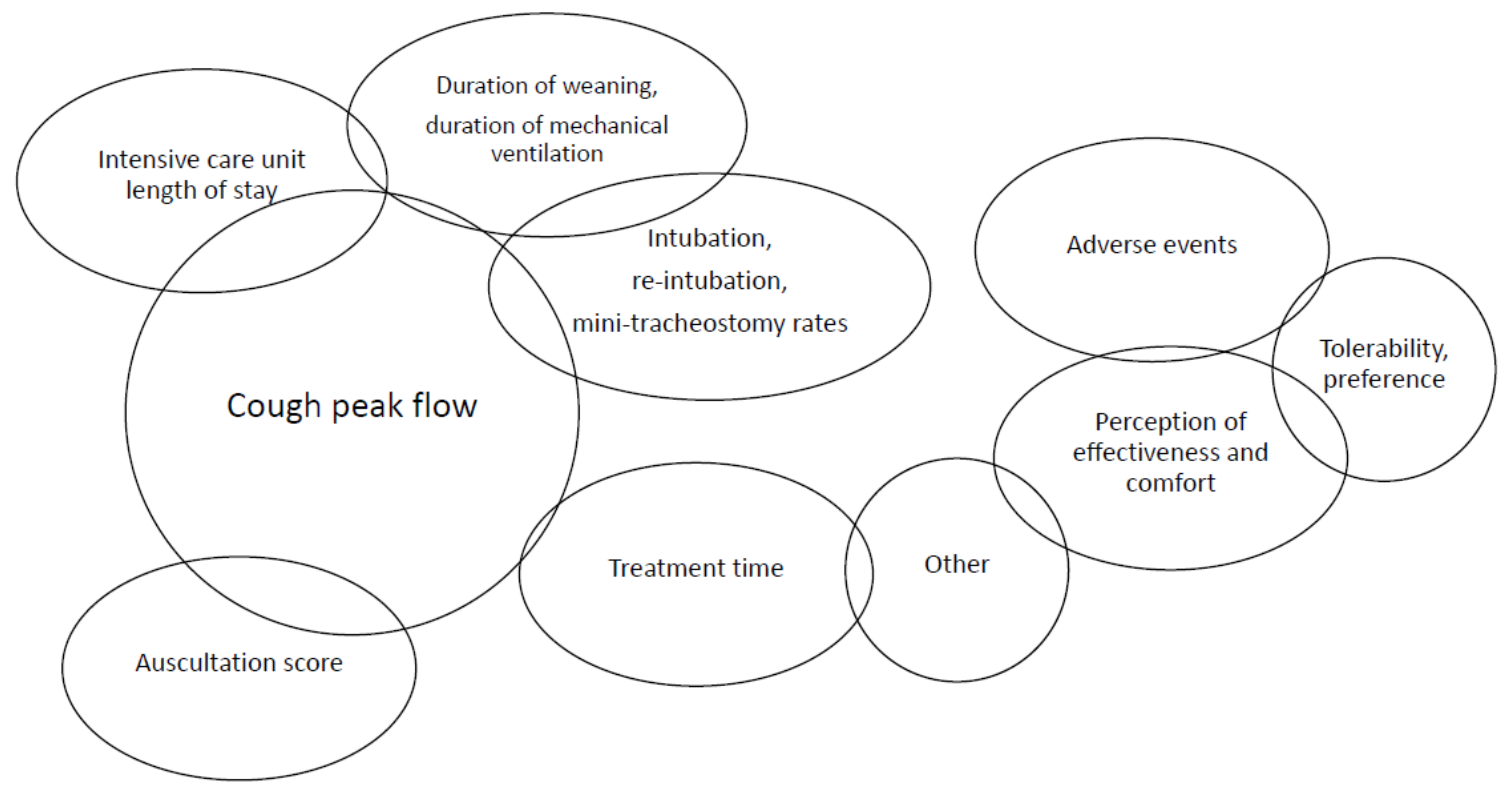

Fig. 1. Outcome measures used to assess the cough augmentation techniques

\section{Patients with chronic obstructive pulmonary disease and individuals with scoliosis}

In a small randomized study, cough augmentation using MAC with or without exsufflation, did not significantly change CPF in nine healthy individuals and decreased the CPF and cough expiratory volume in eight patients with chronic obstructive pulmonary disease (COPD) (Sivasothy et al. 2001). Another study that included nine patients with COPD showed that $\mathrm{CPF}$ did not change significantly with the use of MI-E, but this one involved a higher risk of bias (Winck, Goncalves et al. 2004). Additionally, there was no increase in the CPF in four patients with respiratory muscle weakness with scoliosis, although there was an increase in the patients with respiratory muscle weakness 
without scoliosis (Sivasothy et al. 2001, Chatwin et al. 2003). In contrast, a small study in patients with Duchenne muscular dystrophy did not show a significant difference between the patients who had kyphoscoliosis and those who did not, although this was again a study with higher risk of bias (Brito et al. 2009).

\section{Other outcomes of cough augmentation}

Most studies assess CPF as their primary outcome for investigating the effectiveness of cough augmentation techniques, but other outcomes have also been reported (Fig. 1). A Cochrane review including three studies in mechanically ventilated critically ill patients found no reports about the effect of MI-E on the duration of weaning (Rose et al. 2017). A study with 75 critically ill patients who were receiving mechanical ventilation through endotracheal intubation or tracheostomy, reported higher extubation success (no reintubation within 48 hours) in the group that received MI-E combined with MAC compared to standard care without cough augmentation, $82.9 \%$ vs. $52.5 \%$, p $<0.05$, relative risk $(95 \% \mathrm{CI}) 1.58(1.13,2.20)$ (Goncalves et al. 2012). In another study, the success rates of extubation (no reintubation during hospitalization) for MI-E were $95 \%$ and $91 \%$ in case series with 157 and 98 patients with neuromuscular disease or weakness presenting vital capacities $<20 \%$ of normal values, respectively (Bach et al. 2010, Bach et al. 2015). Furthermore, a study found that the MI-E group had higher success rate for mini tracheostomy and endotracheal intubation compared to usual chest physiotherapy without MI-E, 2/10 vs 10/16, $\mathrm{p}=0.047$ (Vianello et al. 2005).

Evidence indicate a reduction of mechanical ventilation duration and intensive care unit length of stay, but the corresponding level of evidence is low (Niranjan and Bach 1998, Goncalves et al. 2012). There was a reduction in the mechanical ventilation duration for patients who received MI-E, mean difference (95\% CI) 6.1 days $(-8.4,-3.8)$ (Goncalves et al. 2012). Ten patients who underwent tracheostomy and were in the MI-E group, had shorter intensive care unit length of stay than a historical control of patients (3.5 \pm 0.5 days vs. $51.1 \pm 7.8$ days, p<0.001) (Niranjan and Bach 1998). Another study found a lower mean intensive care unit length of stay after extubation in the MI-E group when compared with controls ( $3.1 \pm 2.5$ vs. $9.8 \pm 6.7$ days, $p<0.05)$, but without significant difference in the total intensive care unit length of stay (Goncalves et al. 2012). A small study investigating air stacking vs. MI-E did not show any differences in respiratory tract infections, days on antibiotics, or hospitalisations (Rafiq et al. 2015). On the other hand, MI-E reduced the risk of pneumonia in a retrospective study in 62 children with neuromuscular diseases (Miske et al. 2004).

One systematic review of randomized clinical trials compared the ventilator and manual hyperinflation techniques and found no differences between manual and mechanical hyperinflation, in sputum wet weight, pulmonary compliance, oxygenation and cardiovascular stability (Anderson et al. 2015). A randomized crossover study with eight patients with spinal muscular atrophy and congenital myopathy during an acute respiratory tract infection found that MI-E with MAC decreases the treatment time, improves the auscultation scores and increases the patient-reported effectiveness on the visual analogue scale (Chatwin and Simonds 2009). In a study assessing patient perception of effectiveness and comfort on a visual analogue scale, effectiveness was statistically higher for MI-E with MAC and comfort was higher for hyperinflation and MAC although this was not statistically significant (Lacombe et al. 2014).

Relevant studies do not commonly report mortality, morbidity, quality of life and serious adverse events outcomes (Morrow et al. 2013). One trial reported mortality on intensive care unit within the 48 hours following extubation, but had no participants dying in either group of MI-E or a control group of standard care without cough augmentation (Goncalves et al. 2012). A retrospective study showed that access to non-invasive respiratory aids including MI-E could improve survival, extubation and decannulation in patients with Duchenne muscular dystrophy (Gomez-Merino and Bach 2002). MAC and MI-E, along with oximetry and home use of NIV decreased hospitalizations and respiratory complications and mortality in patients with amyotrophic lateral sclerosis (Vitacca et al. 2010). Long term use of the MI-E can improve vital capacity in neuromuscular disease patients (Stehling et al. 2015).

Furthermore, MI-E was well tolerated in patients with amyotrophic lateral sclerosis and neuromuscular diseases (Winck et al. 2004). A study that included children showed that MI-E was well tolerated, although the children with spinal muscular atrophy generated the lowest CPF values and reported the lowest comfort rates (Fauroux et al. 2008). Patients with spinal cord injury found MI-E more comfortable than suction via endotracheal tube (Sancho et al. 2003). However, patients 
with neuromuscular diseases who use the MI-E as part of their home management, report its size, weight and the burden to the carer as disadvantages (Mahede et al. 2015). The use of MI-E in home care needs to consider social and individual aspects, and health professionals must provide clear instructions, training and confidence to the users, and ensure continuity of care (Moran et al. 2015).

\section{Adverse events of cough augmentation techniques}

Few studies have reported adverse events from cough augmentation techniques when these are applied appropriately. The application of positive pressure could be associated with barotrauma, but the generated pressures are lower than pressures of the physiological cough and of short duration (Gomez-Merino et al. 2002). Pneumothorax is rare, and it was reported when using MI-E and NIV in two patients with neuromuscular disease who had scoliosis (Suri et al. 2008). A study combining MAC with either hyperinflation or MI-E, did not have adverse events (Nijland et al. 2010). A systematic review on manual hyperinflation in intubated and mechanically ventilated patients in the intensive care unit showed that manual hyperinflation resulted in infrequent and short-term adverse events such as decrease in cardiac output, alteration of heart rate and increase in central venous pressures, based on eight out of 13 included studies (Paulus et al. 2012). Although cardiovascular instability risk is low, in glossopharyngeal breathing syncope may occur (Nygren-Bonnier et al. 2018). In a retrospective study, five out of 62 patients with neuromuscular disease (Duchenne muscular dystrophy, spinal muscular atrophy, myopathy and other, including tracheostomy users and children), did not continue the MI-E due to safety issues (Miske et al. 2004). A small study with 16 consecutive patients in the intensive care unit, who were intubated and mechanically ventilated, did not report adverse events with MAC (Avena et al. 2008). The number of patients who required reintubation due to secretions and severe hypoxemia, were nine out of 40 patients $(22.5 \%)$ in the control group of standard care without cough augmentation compared to two out of 35 patients $(6 \%)$ who received MI-E with MAC, relative risk $(95 \% \quad \mathrm{CI}) \quad 0.25 \quad(0.06, \quad 1.10)$ (Goncalves et al. 2012).

A Cochrane review showed that there were no new-onset arrhythmias, heart rate increase $>25 \%$, or pneumothorax for those who received cough augmentation vs. the patients receiving standard care. Still, the studies of this review evaluated a combination of cough augmentation techniques rather than one technique in isolation (Rose et al. 2017). A study reported that one participant in the breath stacking group had an episode of coughing during suctioning, which elevated the participant's blood pressure for more than 30 minutes (Crowe 2006). In a retrospective study with patients with tracheostomy or spinal muscular atrophy, the use of MI-E contributed to chronic abdominal pain, chest discomfort during its application, short-term abnormal cardiac rhythm, but no episodes of pneumothorax (Miske et al. 2004). In one study assessing MI-E in eleven critically ill patients, treatment failed due to repeated episodes of gastroesophageal reflux that resulted in bronchospasm and endotracheal intubation. Also, one patient presented stomach distension but did not discontinue the therapy, whilst another patient developed mild nasal bleeding and discontinued the treatment (Vianello et al. 2005).

\section{Discussion}

Evidence indicate that cough augmentation techniques increase the CPF compared to unassisted cough in patients who present muscle weakness. The CPF increase is greater for the patients who present lower unassisted CPF compared to those with higher values (Mustfa et al. 2003, Ishikawa, Miura et al. 2011). Moreover, cough augmentation techniques seem to have a greater impact on CPF when they target the inspiratory and expiratory cough phases. Still, there is high heterogeneity in the studies that assess the cough augmentation techniques. It is hard to assess the effectiveness of individual techniques over others, as studies applied different treatment arms and in different populations. Most of the studies assessing the cough augmentation techniques have small sample sizes, crossover design, and a short duration (Morrow et al. 2013). Additionally, only few studies were randomized, and the interventions mainly followed a sequence of applying unassisted cough, assisted inspiration, assisted expiration and then the combination of assisted inspiration and expiration. As a result, there is a high risk of bias, particularly in relation to placebo and learning effects (Fauroux et al. 2008). A systematic review with twelve included studies (four randomized controlled trials) showed that there is still poor evidence to guide the 
clinical practice about the application of MI-E in patients with neuromuscular disease (Auger et al. 2017). This was in line with an earlier Cochrane review that analyzed five studies (Morrow et al. 2013).

Researchers and clinicians widely use the CPF values for assessing cough augmentation. Nonetheless, there is a known risk of fixed and proportional bias in assessing CPF with the peak flow meter, which is the outcome that most studies use and a measure that is easy to perform in the clinical setting (Kikuchi et al. 2018, Kulnik et al. 2019). Clinicians need to be cautious when they use the CPF cut off points to guide their clinical decision making for cough augmentation techniques (Kikuchi et al. 2018, Kulnik et al. 2019). They need to assess the evidence about effectiveness, adverse effects, precautions and contraindications of the techniques, alongside patient assessment and ability to perform unsupported coughs. Clinicians, patients and carers also need to consider additional factors such as the tolerance, adherence, treatment burden, knowledge of the technique, confidence, availability of devices, and cost.

\section{Conflict of Interest}

There is no conflict of interest.

\section{References}

ANDERSEN T, SANDNES A, BREKKA AK, HILLAND M, CLEMM H, FONDENES O, TYSNES OB, HEIMDAL JH, HALVORSEN T, VOLLSAETER M, ROKSUND OD: Laryngeal response patterns influence the efficacy of mechanical assisted cough in amyotrophic lateral sclerosis. Thorax 72: 221-229, 2017. https://doi.org/10.1136/thoraxjnl-2015-207555

ANDERSON A, ALEXANDERS J, SINANI C, HAYES S, FOGARTY M: Effects of ventilator vs manual hyperinflation in adults receiving mechanical ventilation: a systematic review of randomized clinical trials. Physiotherapy 101: 103-110, 2015. https://doi.org/10.1016/j.physio.2014.07.006

AUGER C, HERNANDO V, GALMICHE H: Use of mechanical insufflation-exsufflation devices for airway clearance in subjects with neuromuscular disease. Respir Care 62: 236-245, 2017. https://doi.org/10.4187/respcare.04877

AVENA KDE M, DUARTE AC, CRAVO LS, SOLOGUREN MJ, GASTALDI AC: Effects of manually assisted coughing on respiratory mechanics in patients requiring full ventilatory support. J Bras Pneumol 34: 380-386, 2008. https://doi.org/10.1590/S1806-37132008000600008

BACH JR: Mechanical insufflation-exsufflation. Comparison of peak expiratory flows with manually assisted and unassisted coughing techniques. Chest 104: 1553-1562, 1993. https://doi.org/10.1378/chest.104.5.1553

BACH JR, GONCALVES MR, HAMDANI I, WINCK JC: Extubation of patients with neuromuscular weakness: a new management paradigm. Chest 137: 1033-1039, 2010. https://doi.org/10.1378/chest.09-2144

BACH JR, SAPORITO LR, SHAH HR, SINQUEE D: Decanulation of patients with severe respiratory muscle insufficiency: efficacy of mechanical insufflation-exsufflation. J Rehabil Med 46: 1037-1041, 2014. https://doi.org/10.2340/16501977-1874

BACH JR, SINQUEE DM, SAPORITO LR, BOTTICELLO AL: Efficacy of mechanical insufflation-exsufflation in extubating unweanable subjects with restrictive pulmonary disorders. Respir Care 60: 477-483, 2015. https://doi.org/10.4187/respcare.03584

BACH JR, SMITH WH, MICHAELS J, SAPORITO L, ALBA AS, DAYAL R, PAN J: Airway secretion clearance by mechanical exsufflation for post-poliomyelitis ventilator-assisted individuals. Arch Phys Med Rehabil 74: 170$177,1993$.

BIANCHI C, CARRARA R, KHIRANI S, TUCCIO MC: Independent cough flow augmentation by glossopharyngeal breathing plus table thrust in muscular dystrophy. Am J Phys Med Rehabil 93: 43-48, 2014. https://doi.org/10.1097/PHM.0b013e3182975bfa

BIANCHI C, GRANDI M, FELISARI G: Efficacy of glossopharyngeal breathing for a ventilator-dependent, high-level tetraplegic patient after cervical cord tumor resection and tracheotomy. Am J Phys Med Rehabil 83: 216-219, 2004. https://doi.org/10.1097/01.PHM.0000113408.96258.06

BIRRING SS, PRUDON B, CARR AJ, SINGH SJ, MORGAN MDL, PAVORD ID: Development of a symptom specific health status measure for patients with chronic cough: Leicester Cough Questionnaire (LCQ). Thorax 58: 339-343, 2003. https://doi.org/10.1136/thorax.58.4.339 
BRAUN SR, GIOVANNONI R, O'CONNOR M: Improving the cough in patients with spinal cord injury. Am J Phys Med 63: 1-10, 1984.

BRITO MF, MOREIRA GA, PRADELLA-HALLINAN M, TUFIK S: Air stacking and chest compression increase peak cough flow in patients with Duchenne muscular dystrophy. J Bras Pneumol 35: 973-979, 2009. https://doi.org/10.1590/S1806-37132009001000005

CHATWIN M, ROSS E, HART N, NICKOL AH, POLKEY MI, SIMONDS AK: Cough augmentation with mechanical insufflation/exsufflation in patients with neuromuscular weakness. Eur Respir J 21: 502-508, 2003. https://doi.org/10.1183/09031936.03.00048102

CHATWIN M, SIMONDS AK: The addition of mechanical insufflation/exsufflation shortens airway-clearance sessions in neuromuscular patients with chest infection. Respir Care 54: 1473-1479, 2009.

CHATWIN M, SIMONDS AK: Long-term mechanical insufflation-exsufflation cough assistance in neuromuscular disease: patterns of use and lessons for application. Respir Care 54: 1473-1479, 2009.

CHATWIN M, TOUSSAINT M, GONCALVES MR, SHEERS N, MELLIES U, GONZALES-BERMEJO J, SANCHO J, FAUROUX B, ANDERSEN T, HOV B, NYGREN-BONNIER M, LACOMBE M, PERNET K, KAMPELMACHER M, DEVAUX C, KINNETT K, SHEEHAN D, RAO F, VILLANOVA M, BERLOWITZ D, MORROW MB: Airway clearance techniques in neuromuscular disorders: A state of the art review. Respir Med 136: 98-110, 2018. https://doi.org/10.1016/j.rmed.2018.01.012

CROWE J, RAJCZAK J, ELMS B: Safety and effectiveness of breath stacking in management of persons with acute atelectasis. Physiotherapy Canada 58: 306-314, 2006. https://doi.org/10.3138/ptc.58.4.306

DENEHY L: The use of manual hyperinflation in airway clearance. Eur Respir J14: 958-965, 1999. https://doi.org/10.1034/j.1399-3003.1999.14d38.x

DENNIS D, JACOB W, BUDGEON C: Ventilator versus manual hyperinflation in clearing sputum in ventilated intensive care unit patients. Anaesth Intensive Care 40: 142-149, 2012. https://doi.org/10.1177/0310057X1204000117

DOHNA-SCHWAKE C, RAGETTE R, TESCHLER H, VOIT T, MELLIES U: IPPB-assisted coughing in neuromuscular disorders. Pediatr Pulmonol 41: 551-557, 2006. https://doi.org/10.1002/ppul.20406

FAUROUX B, GUILLEMOT N, AUBERTIN G, NATHAN N, LABIT A, CLEMENT A, LOFASO F: Physiologic benefits of mechanical insufflation-exsufflation in children with neuromuscular diseases. Chest 133: 161-168, 2008. https://doi.org/10.1378/chest.07-1615

FEIGELSON CI, DICKINSON DG, TALNER NS, WILSON LW: Glossopharyngeal breathing as an aid to the coughing mechanism in the patient with chronic poliomyelitis in a respirator. N Engl J Med 254: 611-613, 1956. https://doi.org/10.1056/NEJM195603292541306

GOMEZ-MERINO E, BACH JR: Duchenne muscular dystrophy: prolongation of life by noninvasive ventilation and mechanically assisted coughing. Am J Phys Med Rehabil 81: 411-415, 2002. https://doi.org/10.1097/00002060-200206000-00003

GOMEZ-MERINO E, SANCHO J, MARIN J, SERVERA E, BLASCO ML, BELDA FJ, CASTRO C, BACH JR: Mechanical insufflation-exsufflation: pressure, volume, and flow relationships and the adequacy of the manufacturer's guidelines. Am J Phys Med Rehabil 81: 579-583, 2002. https://doi.org/10.1097/00002060200208000-00004

GONCALVES MR, HONRADO T, WINCK JC, PAIVA JA: Effects of mechanical insufflation-exsufflation in preventing respiratory failure after extubation: a randomized controlled trial. Crit Care 16: R48, 2012. https://doi.org/10.1186/cc11249

GUERIN C, BOURDIN G, LERAY V, DELANNOY B, BAYLE F, GERMAIN M, RICHARD JC: Performance of the coughassist insufflation-exsufflation device in the presence of an endotracheal tube or tracheostomy tube: a bench study. Respir Care 56: 1108-1114, 2011. https://doi.org/10.4187/respcare.01121

HOMNICK DN: Mechanical insufflation-exsufflation for airway mucus clearance. Respir Care 52: 1296-1305, 2007.

HOV B, ANDERSEN T, HOVLAND V, TOUSSAINT M: The clinical use of mechanical insufflation-exsufflation in children with neuromuscular disorders in Europe. Paediatr Respir Rev 27: 69-73, 2018. https://doi.org/10.1016/j.prrv.2017.08.003 
HULL J, ANIAPRAVAN R, CHAN E, CHATWIN M, FORTON J, GALLAGHER J. GIBSON N, GORDON J. HUGHES I, MCCULLOCH R, RUSSELL RR, SIMONDS A: British Thoracic Society guideline for respiratory management of children with neuromuscular weakness. Thorax 67 Suppl 1: i1-40, 2012. https://doi.org/10.1136/thoraxjnl-2012-201964

ISHIKAWA Y, MIURA T, ISHIKAWA Y, AOYAGI T, OGATA H, HAMADA S, MINAMI R: Duchenne muscular dystrophy: survival by cardio-respiratory interventions. Neuromuscul Disord 21: 47-51, 2011. https://doi.org/10.1016/j.nmd.2010.09.006

JAEGER RJ, TURBA RM, YARKONY GM, ROTH EJ: Cough in spinal cord injured patients: comparison of three methods to produce cough. Arch Phys Med Rehabil 74: 1358-1361, 1993. https://doi.org/10.1016/00039993(93)90093-P

KAN AF, BUTLER JM, HUTCHENCE M, JONES K, WIDGER J, DOUMIT MA: Teaching manually assisted cough to caregivers of children with neuromuscular disease. Respir Care 63: 1520-1527, 2018. https://doi.org/10.4187/respcare.06213

KANG SW, BACH JR: Maximum insufflation capacity: vital capacity and cough flows in neuromuscular disease. Am J Phys Med Rehabil 79: 222-227, 2000. https://doi.org/10.1097/00002060-200005000-00002

KANG SW, KANG YS, MOON JH, YOO TW: Assisted cough and pulmonary compliance in patients with Duchenne muscular dystrophy. Yonsei Med J 46: 233-238, 2005. https://doi.org/10.3349/ymj.2005.46.2.233

KANG SW, SHIN JC, PARK CI, MOON JH, RHA DW, CHO DH: Relationship between inspiratory muscle strength and cough capacity in cervical spinal cord injured patients. Spinal Cord 44: 242-248, 2006. https://doi.org/10.1038/sj.sc.3101835

KIKUCHI K, SATAKE M, KIMOTO Y, IWASAWA S, SUZUKI R, KOBAYASHI M, WADA C, SHIOYA T: Approaches to cough peak flow measurement with Duchenne muscular dystrophy. Respir Care 63: 1514-1519, 2018. https://doi.org/10.4187/respcare.06124

KIM SM, CHOI WA, WON YH, KANG SW: A Comparison of cough assistance techniques in patients with respiratory muscle weakness. Yonsei Med J 57: 1488-1493, 2016. https://doi.org/10.3349/ymj.2016.57.6.1488

KIRBY NA, BARNERIAS MJ, SIEBENS AA: An evaluation of assisted cough in quadriparetic patients. Arch Phys Med Rehabil 47: 705-710, 1966.

KULNIK ST, MACBEAN V, LEWKO A, SPINOU A: Accuracy in the assessment of cough peak flow: good progress for a 'work in progress'. Respir Care 65: 133-134, 2020. https://doi.org/10.4187/respcare.07454

LACOMBE ML, DEL AMO CASTRILLO L, BORE A, CHAPEAU D, HORVAT E, VAUGIER I, LEJAILLE M, ORLIKOWSKI D, PRIGENT H, LOFASO F: Comparison of three cough-augmentation techniques in neuromuscular patients: mechanical insufflation combined with manually assisted cough, insufflationexsufflation alone and insufflation-exsufflation combined with manually assisted cough. Respiration 88: 215 222, 2014. https://doi.org/10.1159/000364911

LEE KK, MATOS S, WARD K, RAFFERTY GF, MOXHAM J, EVANS DH, BIRRING SS: Sound: a non-invasive measure of cough intensity. BMJ Open Respir Res 4: e00178, 2017. https://doi.org/10.1136/bmjresp-2017$\underline{000178}$

MAHEDE T, DAVIS G, RUTKAY A, BAXENDALE S, SUN W, DAWKINS HJ, MOLSTER D, GRAHAM CE: Use of mechanical airway clearance devices in the home by people with neuromuscular disorders: effects on health service use and lifestyle benefits. Orphanet J Rare Dis 10: 54, 2015.https://doi.org/10.1186/s13023-015-0267-0

MARQUES TB, NEVES JDE C, PORTES LA, SALGE JM, ZANOTELI E, REED UC: Air stacking: effects on pulmonary function in patients with spinal muscular atrophy and in patients with congenital muscular dystrophy. J Bras Pneumol 40: 528-534, 2014. https://doi.org/10.1590/S1806-37132014000500009

MCCOOL FD: Global physiology and pathophysiology of cough: ACCP evidence-based clinical practice guidelines. Chest 129 (1 Suppl): 48-53, 2006. https://doi.org/10.1378/chest.129.1_suppl.48S

MELLIES U, GOEBEL C: Optimum insufflation capacity and peak cough flow in neuromuscular disorders." Ann Am Thorac Soc 11: 1560-1568, 2014. https://doi.org/10.1513/AnnalsATS.201406-2640C

MISKE LJ, HICKEY EM, KOLB SM, WEINER DJ, PANITCH HB: Use of the mechanical in-exsufflator in pediatric patients with neuromuscular disease and impaired cough. Chest 125: 1406-1412, 2004. https://doi.org/10.1378/chest.125.4.1406 
MORAN FC, SPITTLE AJ, DELANY C: lifestyle implications of home mechanical insufflation-exsufflation for children with neuromuscular disease and their families. Respir Care 60: 967-974, 2015. https://doi.org/10.4187/respcare.03641

MORROW B, ZAMPOLI M, VAN ASWEGEN H, ARGENT A: Mechanical insufflation-exsufflation for people with neuromuscular disorders. Cochrane Database Syst Rev Cd010044, 2013. https://doi.org/10.1002/14651858.CD010044.pub2

MUSTFA N, AIELLO M, LYALL RA, NIKOLETOUD, OLIVIERI D, LEIGH PN, DAVIDSON AC, POLKEY MI, MOXHAM J: Cough augmentation in amyotrophic lateral sclerosis. Neurology 61: 1285-1287, 2003. https://doi.org/10.1212/01.WNL.0000092018.56823.02

NIJLAND N, CRANEN K, BOER H, VAN GEMERT-PIJNEN JE, SEYDEL ER: Patient use and compliance with medical advice delivered by a web-based triage system in primary care. J Telemed Telecare 16: 8-11, 2010. https://doi.org/10.1258/jtt.2009.001004

NIRANJAN V, BACH JR: Noninvasive management of pediatric neuromuscular ventilatory failure. Crit Care Med 26: 2061-2065, 1998.https://doi.org/10.1097/00003246-199812000-00042

NYGREN-BONNIER M, SCHIFFER TA, LINDHOLM P: Acute effects of glossopharyngeal insufflation in people with cervical spinal cord injury. J Spinal Cord Med 41: 85-90, 2018. https://doi.org/10.1080/10790268.2016.1275446

NYGREN-BONNIER M, WERNER J, BIGUET G, JOHANSSON S: Instead of popping pills, perhaps you should add frog breathing': experiences of glossopharyngeal insufflation/breathing for people with cervical spinal cord injury. Disabil Rehabil 40: 1639-1645, 2018. https://doi.org/10.1080/09638288.2017.1304583

PAULUS F, BINNEKADE JM, VROOM MB, SCHULTZ MJ: Benefits and risks of manual hyperinflation in intubated and mechanically ventilated intensive care unit patients: a systematic review. Crit Care 16: R145, 2012. https://doi.org/10.1186/cc11457

PREVOST S, BROOKS D, BWITITI PT: Mechanical insufflation-exsufflation: Practice patterns among respiratory therapists in Ontario. Can J Respir Ther 51: 33-38, 2015.

RAFIQ MK, BRADBURN M, PROCTOR AR, BILLINGS CG, BIANCHI S, MCDERMOTT SJ, SHAW PJ: A preliminary randomized trial of the mechanical insufflator-exsufflator versus breath-stacking technique in patients with amyotrophic lateral sclerosis. Amyotroph Lateral Scler Frontotemporal Degener 16: 448-455, 2015. https://doi.org/10.3109/21678421.2015.1051992

ROSE L, ADHIKARI NK, LEASA D, FERGUSON D, MCKIM DA: Cough augmentation techniques for extubation or weaning critically ill patients from mechanical ventilation. Cochrane Database Syst Rev 1: Cd011833, 2017. https://doi.org/10.1002/14651858.CD011833.pub2

ROSE L, MCKIM D, KATZ S, LEASA D, NONOYAMA M, PEDERSEN C, AVENDANO M, GOLDSTEIN R: Institutional care for long-term mechanical ventilation in Canada: A national survey. Can Respir J 21: 357-362, 2014. https://doi.org/10.1155/2014/538687

SANCHO J, SERVERA A, BANULS P, MARIN J: Effectiveness of assisted and unassisted cough capacity in amyotrophic lateral sclerosis patients. Amyotroph Lateral Scler Frontotemporal Degener 18: 498-504, 2017. https://doi.org/10.1080/21678421.2017.1335324

SANCHO J, SERVERA E, DIAZ J, MARIN J: Efficacy of mechanical insufflation-exsufflation in medically stable

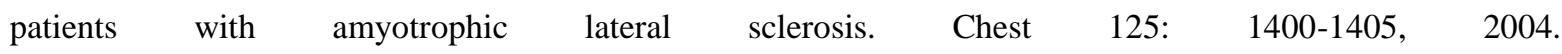
https://doi.org/10.1378/chest.125.4.1400

SANCHO J, SERVERA E, VERGARA P, MARIN J: Mechanical insufflation-exsufflation vs. tracheal suctioning via tracheostomy tubes for patients with amyotrophic lateral sclerosis: a pilot study. Am J Phys Med Rehabil 82: 750-753, 2003. https://doi.org/10.1097/01.PHM.0000087456.28979.2E

SARMENTO A, RESQUETI V, DOURADO-JUNIOR M, SATURNINO L, ALIVERTI A, FREGONEZI G, DE ANDRADE AD: Effects of air stacking maneuver on cough peak flow and chest wall compartmental volumes of subjects with amyotrophic lateral sclerosis. Arch Phys Med Rehabil 98: 2237-2246, 2017. https://doi.org/10.1016/j.apmr.2017.04.015

SENENT C, GOLMARD JL, SALACHAS F, CHINER E, MORELOT-PANZINI C, MENINGER V, LAMOUROUX C, SIMILOWSKI T, GONZALEZ-BERMEJO J: A comparison of assisted cough techniques in stable patients 
with severe respiratory insufficiency due to amyotrophic lateral sclerosis. Amyotroph Lateral Scler 12: 26-32, 2011. https://doi.org/10.3109/17482968.2010.535541

SILVA AR, FLUHR SA, BEZERRA ADE L, CORREIA JR M, FRANCA EE, ANDRADE MF: Expiratory peak flow and respiratory system resistance in mechanically ventilated patients undergoing two different forms of manually assisted cough. Rev Bras Ter Intensiva 24: 58-63, 2012. https://doi.org/10.1590/S0103$\underline{507 X 2012000100009}$

SIVASOTHY P, BROWN L, SMITH IE, SHNEERSON JM: Effect of manually assisted cough and mechanical insufflation on cough flow of normal subjects, patients with chronic obstructive pulmonary disease (COPD), and patients with respiratory muscle weakness. Thorax 56: 438-444, 2001. https://doi.org/10.1136/thorax.56.6.438

SPINOU A: Non-pharmacological techniques for the extremes of the cough spectrum. Respir Physiol Neurobiol 257: 511, 2018. https://doi.org/10.1016/j.resp.2018.03.006

SPINOU A, BIRRING SS: An update on measurement and monitoring of cough: what are the important study endpoints? J Thoracic Dis 6 (Suppl 7): S728-S734, 2014. https://doi.org/10.3978/j.issn.2072-1439.2014.10.08

SPINOU A, LEE KK, SINHA A, ELSTON C, LOEBINGER MR, WILSON R, CHUNG KF, YOUSAF N, PAVORD ID, MATOS S, GARROD R, BIRRING SS: The Objective Assessment of Cough Frequency in Bronchiectasis. Lung 195: 575-585, 2017. https://doi.org/10.1007/s00408-017-0038-x.

MATOS S, GARROD R, BIRRING SS: The objective assessment of cough frequency in bronchiectasis. Lung 195: 575-585, 2017. https://doi.org/10.1007/s00408-017-0038-x

STEHLING F, BOUIKIDIS A, SCHARA U, MELLIES U: Mechanical insufflation/exsufflation improves vital capacity in neuromuscular disorders. Chron Respir Dis 12: 31-35, 2015. https://doi.org/10.1177/1479972314562209

STRIEGL AM, REDDING GJ, DIBLASI R, CROTWELL D, SALYER J, CARTER ER: Use of a lung model to assess mechanical in-exsufflator therapy in infants with tracheostomy. Pediatr Pulmonol 46: 211-217, 2011. https://doi.org/10.1002/ppul.21353

SURI P, BURNS SP, BACH JR: Pneumothorax associated with mechanical insufflation-exsufflation and related factors." Am J Phys Med Rehabil 87: 951-955, 2008. https://doi.org/10.1097/PHM.0b013e31817c181e

TOUSSAINT M, BOITANO LJ, GATHOT V, STEENS M, SOUDON P: Limits of effective cough-augmentation techniques in patients with neuromuscular disease. Respir Care 54: 359-366, 2009.

TREBBIA G, LACOMBE M, FERMANIAN C, FALAIZE L, LEJAILLE M, LOUIS A, DEVAUX C, RAPHAEL JC, LOFASO C: Cough determinants in patients with neuromuscular disease. Respir Physiol Neurobiol 146: 291 300, 2004. https://doi.org/10.1016/j.resp.2005.01.001

VIANELLO AA, CORRADO G, ARCARO F, GALLAN C, ORI M, MINUZZO M, BEVILACQUA M: Mechanical insufflation-exsufflation improves outcomes for neuromuscular disease patients with respiratory tract infections. Am J Phys Med Rehabil 84: 83-88, 2005. https://doi.org/10.1097/01.PHM.0000151941.97266.96

VITACCA M, PANERONI M, TRAININI D, BIANCHI L, ASSONI G, SALERI M, GILE S, WINCK JC, GONCALVES MR: At home and on demand mechanical cough assistance program for patients with amyotrophic lateral sclerosis. Am J Phys Med Rehabil 89: 401-406, 2010. https://doi.org/10.1097/PHM.0b013e3181d89760

WIDDICOMBE J, FONTANA G: Cough: what's in a name? Eur Respir J 28: 10-15, 2004. https://doi.org/10.1183/09031936.06.00096905

WINCK JC, GONCLAVES MR, LOURENO C, VIANA P, ALMEDIA J, BACH JR: Effects of mechanical insufflation-exsufflation on respiratory parameters for patients with chronic airway secretion encumbrance. Chest 126: 774-780, 2004. https://doi.org/10.1378/chest.126.3.774 